\title{
Ergonomics and sustainability: towards an embrace of complexity and emergence
}

\author{
Sidney W.A. Dekker ${ }^{\mathrm{a} *}$, Peter A. Hancock ${ }^{\mathrm{b}}$ and Peter Wilkin ${ }^{\mathrm{c}}$ \\ ${ }^{a}$ School of Humanities, Griffith University, 170 Kessels Road, Nathan Campus, QLD 4111, Australia; ${ }^{b}$ Department of Psychology \\ and Institute for Simulation and Training, University of Central Florida, Orlando, FL, USA; ${ }^{c}$ School of Social Science, Brunel \\ University, Uxbridge, Middlesex UB8 3PH, UK
}

(Received 5 September 2011; final version received 2 August 2012)

\begin{abstract}
Technology offers a promising route to a sustainable future, and ergonomics can serve a vital role. The argument of this article is that the lasting success of sustainability initiatives in ergonomics hinges on an examination of ergonomics' own epistemology and ethics. The epistemology of ergonomics is fundamentally empiricist and positivist. This places practical constraints on its ability to address important issues such as sustainability, emergence and complexity. The implicit ethical position of ergonomics is one of neutrality, and its positivist epistemology generally puts value-laden questions outside the parameters of what it sees as scientific practice. We argue, by contrast, that a discipline that deals with both technology and human beings cannot avoid engaging with questions of complexity and emergence and seeking innovative ways of addressing these issues.
\end{abstract}

Practitioner Summary: Ergonomics has largely modelled its research on a reductive science, studying parts and problems to fix. In sustainability efforts, this can lead to mere local adaptations with a negative effect on global sustainability. Ergonomics must consider quality of life globally, appreciating complexity and emergent effects of local relationships.

Keywords: sustainability; ergonomics; epistemology; ethics; complexity; emergence

\section{Introduction}

In this article, we argue that the success of ergonomics in promoting sustainable societies needs to be founded upon an examination of the field's own epistemology and ethics. There are several reasons for this. Firstly, mainstream ergonomics espouses a basic philosophical stance, whether explicitly acknowledged or not, which is positivist and empiricist (Wilkin 2009, Dekker et al. 2010). This doctrine has profoundly important implications for the way in which practitioners are trained, for what is included in and excluded from the field, and for what its legitimate research questions are considered to be (Kuorinka 1990). Secondly, ergonomics has an important and potentially crucial role to play in all sustainability efforts. Technology offers a promising route to a sustainable future, and the way in which humans and technology integrate and coordinate their actions (a question central to ergonomics) is fundamental to the success of this development (Hancock 2009). Technology, however, can be put to many purposes, and its development and manufacture touch on many more lives than just the end users. Judgements about what is the right (or sustainable) thing to do can only be made in the context of the circumstances in which the technology is created and applied. Such a normative aspect to the role of ergonomics is unavoidable here, and this article argues that ergonomics should actively engage with debates about technology, complexity, emergence and ethics that are a staple of the humanities and social sciences. In order to build its case, this article concentrates on three main issues: firstly, it addresses the epistemological assumptions underpinning ergonomics as a discipline and the ethical issues that arise out of this; secondly, it introduces the issue of sustainability and the problems that this raises for ergonomic practice; thirdly, it addresses the issues of sustainability, complexity and emergence and shows why ergonomics needs to broaden its intellectual framework.

\section{The epistemology of ergonomics}

We begin this article by focusing on the epistemological foundations of ergonomics. This is what establishes the scientific framework of rules and norms that guide its scientific practice. In doing so, we show that these foundations are now highly problematic as ergonomics has to deal with problems of complexity, emergence and sustainability which cannot be easily reconciled with its positivist intellectual lineage.

*Corresponding author. Email: s.dekker@griffith.edu.au 
Despite initiatives to the contrary (Rochlin 1999, Vicente 2000, Woods and Dekker 2001, Hancock et al. 2002, Waterson 2009, Carayon 2010, Dekker 2011b, Goh et al. 2010), the epistemology of mainstream ergonomics remains fundamentally empiricist and positivist. This is in part a remnant of its roots in engineering (Roscoe 1997, Meister 1999) but also driven by the desire for the systematic, unified production of evidence. This helps buttress the self-confidence of ergonomics as a scientific enterprise (Dekker 2005, Dekker et al. 2010), a longing for scientific respectability that can also be found in other disciplines that straddle the natural and social sciences such as psychology and economics. It echoes early twentieth-century debates in psychology that saw the emergence of behaviourist psychology as an 'objective' approach to the subject which allegedly excluded the problematic 'subjective' aspect of human consciousness (Watson, J.B. 1913, Watson, R.I. 1978, Hancock et al. 2002). Ergonomics, too, has shared the goal of behavioural psychology in its ambition to establish itself as a hard science, but we aim to show the problems that such assumptions bring to any discipline, including ergonomics, which addresses both technology and the human being.

Like many of the sciences on the threshold between the designations 'hard' and 'soft' (Wallerstein 1996), ergonomics involves accumulating facts about constructs which themselves have often generated both the demand for the facts and the criteria by which they are defined (Xiao and Vicente 2000, Parasuraman et al. 2008). For example, ergonomics has taken part in the struggle to define and measure many nominally behavioural attributes such as mental workload, attention, fatigue, situation awareness and others - all of which have proven to be pragmatically useful but theoretically 'slippery' constructs (Sarter and Woods 1991, Flach 1995, Smith and Hancock 1995). Such generation and usage of knowledge has multiple consequences. For one, it constrains how ergonomics characterises research problems. In this respect, the epistemological foundation of ergonomics acts as a paradigm, as Kuhn argued in his now famous account of the development of scientific knowledge. By this is meant that it establishes a framework of rules through which questions and answers are established for particular disciplines (Feyerabend 1993). This framework enables both productive and useful activities but also constrains it by establishing a normative boundary which rules out certain kinds of questions and answers as being beyond the framework of the discipline. Kuhn's work has been profoundly influential across the natural and social sciences and has echoes in the work of other figures such as Foucault's work (1970) on what he termed Epistemes, a similar account of the normative framework established by distinct bodies of thought and practice such as medicine, psychiatry and criminology. Thus, the variables and associated interactions that can be determined and measured according to ergonomic orthodoxy are enabled and constrained by the paradigm itself (Parasuraman et al. 2008). This inherently limits ergonomics' ethical explorations of its own contributions and values, because the possibility of asking normative questions that relate directly to its activities is often excluded. Questions about ergonomics' values can be safely limited to local gains in usability, comfort, efficiency or quality of life (Hancock 2009), or, for the present issue, sustainability.

These epistemological and ethical characteristics of ergonomics limit the validity of almost any ergonomic contribution to sustainability. These limits have to do with the epistemological and ideological space that ergonomics has created for itself - a space defined not only because of its intellectual roots in engineering and psychology, but also through its historical profile of research funding and its institutional interconnections (Hancock and Drury 2011). Despite forays into sociology and ethnography, most work in ergonomics still typically studies its world as a series of closed systems. The ideal study is one where all parts can be known and controlled as variables whose interactions take the form of a constant conjunction of events and correlations (Endsley 1995, Wiegmann et al. 2002). In these restrictively closed worlds, ergonomics promises its stakeholders to solve their appropriately circumscribed problems instrumentally, pragmatically (Parasuraman et al. 2008). As with any purely empiricist science, it assumes that what is knowable is ultimately that which can be seen, and if it cannot be seen, it has to be reduced to something that can be (Wilkin 2009). The social systems of ergonomics, such as individuals working in an office or aircraft cockpit, consist of discrete units and their interactions, always clearly bounded and always visible, and thus nominally measurable (Hutchins 1995, Sarter and Woods 1997).

However, as we argue, this paradigm has its own limitations and it is our aspiration that ergonomics, especially as it can be applied to the wider issues engendered by an agenda of sustainability, needs to and can reach beyond this framework to engage meaningfully with other disciplines. The accounts ergonomics generates about the social world are limited and partial, in keeping with its positivist approach, and organised around technical-componential reduction and problem-solving. Within the conventional field of enquiry, ergonomic questions readily default to the constraints of the paradigm: the computable variable, the perceptible result. This is not a nefarious intention, to be sure. It is the way things are done inside the discipline, the method and procedures by which legitimate data are generated, the episteme that governs its production of both science and practical guidance (Foucault 1970). Our aim, however, is to make sure that ergonomics is aware of its way of not seeing things. We need to make sure that it does 
not avoid as a matter of common sense, or as a positivist consensus on what counts as scientific (Parasuraman et al. 2008), the sorts of questions that are central to any meaningful analysis of social institutions and relations. Power, class, social conflict or the far-flung reverberations of Western lifestyle choices are among those categories of the social order which we should make discernible in ergonomic orthodoxy.

It was the late Hal Hendrick, one-time President of both the Human Factors and Ergonomics Society and the International Ergonomics Association, who famously asserted that good ergonomics is good economics. Deploying the phonetic similarity between the two terms, Hendrick aimed to show that applying ergonomics to the workplace enhances profit margins - not only by increasing production efficiency but also by limiting threats to the health and safety of workers (and, accordingly, to the bottom line of the company). Whether considered to be true or not, this epithet explicitly argued that ergonomics offers a win-win for employers and worker (as well as associated institutional stakeholders). In any discussion of sustainability, this proposition puts two notions to the test. The first is the relationship between good economics and the quality of life. The second is that it takes for granted that good economics is itself good. Critical questions about the fundamental nature of sustainability challenge both those ideas. In any system of production, working people readily become the means to an end (often somebody else's end). This arrangement has benefited the quality of life of only a relative few, often to the detriment of that of many. Hendrick's comment served to reify and perpetuate this unequal exchange, something that may not have changed much to this day. More pointedly and in line with Kuhn's ideas about paradigm and Foucault's notion of an episteme, it naturalised the assumption that ergonomics can legitimately be a technical practice whose intellectual boundary is set by its role in generating profit as the primary good. Whether ergonomics is capable of enhancing the quality of life is not just a matter of deciding where to stop measuring but is also a matter of the ends to which it is put. As one of us (Wilkin 2009, p. 233) has noted elsewhere:

Ergonomics is a discipline that adopts a technical and problem-solving approach to the problems it faces, which allows it to avoid deeper social questions about the nature of power in the workplace, social conflict, the control of and access to resources and the importance of capitalism as a social and economic system that generates the problems that ergonomics attempts to deal with.

Thus, a question ergonomics does not tend to specify is: whose quality of life is we concerned with? For the purpose of the theme of this special issue, the question becomes: the sustainability of whose way of life? This invokes the deeper questions of power and social conflict which ergonomics in general has tacitly ignored (Antonsen 2009, Silbey 2009). We turn now to three concepts that present significant problems for conventional ergonomic epistemology. These underline the call for ergonomics to broaden its intellectual horizons and, consequently, its theoretical, practical and educational concerns.

\section{Sustainability, complexity and emergence: three fundamental problems for ergonomics}

Perhaps without knowing it, ergonomics has always been an inherent part of debates and struggles about how we should live, work, travel, enjoy leisure or many other aspects of human existence. In short, it is part of the discourse on what political philosophy has long called the good life. Indeed, ergonomics has an important part to play in ideas about building or designing a good society. But, in order to do so, it needs to embrace issues outside of its normal scientific practice. Specifically, these are the issues encompassed by the terms of sustainability, complexity and emergence. What is urgently needed within ergonomics is an open and expansive discussion about its possibilities but also its inherent obstacles for actively contributing to this debate. For example, burgeoning insights in postNewtonian approaches to science illustrate the significance of complexity for an understanding of the natural and social world. These lead to the 'end of certainty' but also to an understanding of emergence, holism and complexity (Wallerstein 1996, Cilliers 1998, 2002, Page 2008). Learning from such insights is fundamental to any discipline dealing with the problem of sustainability (Capra 1996) and can help ergonomics better discern its role and responsibilities.

\section{Complexity and sustainability}

Complex systems consist of numerous structures and agents that are interrelated in elaborate and elaborative ways, and they are open systems. They can never be known fully, constantly change in interaction with their environment, and their boundaries are fuzzy (Flach et al. 2008, Wagenmakers et al. 2012). It can be hard to find out (or may well be ultimately arbitrary) where the system ends and the environment begins. Complexity theory stresses the importance of local relationships (Cilliers 1998). A complex system is held together only by its local relationships, as 
there is no governor or central agency with the cognitive capacity to understand (let alone control) how the complex system works (Dekker et al. 2011). Local relationships in one part of a complex system link into local relationships of other regions, multiplying, rippling and reverberating in ways that become ever harder to trace, and progressively easier to dismiss or omit from one's own responsibility (Heylighen et al. 2006). The actions one takes in a complex system control very little, but influence almost everything (Page 2008). For an example of local ergonomic improvements in usability, size, shape and even aesthetics that sacrifice sustainability far away from the point of use, consider the connection between the consumption of cell phones and the threat to mountain gorillas in the Congo (Dekker 2011a, Redmond 2001). There is no clear line which runs from one to the other, but a multiplicity of local relationships that diffuse across the world to create and feed a market for coltan, or columbite-tantalite, a metallic ore that becomes a heat resistant powder with unique properties for storing electrical charge (tantalum capacitors control current flow in cell phone circuit boards). The local relationships that link cell phones to gorillas run through and connect the illegal exploitation of small rivers and streams in national parks in East Africa. In this Web of interactivity, Rwanda was, for a time, the world's largest exporter of coltan, even though it has no coltan in its own soil. The reticulation is linked through regional conflict, child- and indentured labour, small arms smuggling, neo-colonialism, environmental destruction, resource depletion and species extinction through the hunting of 'bush meat' and habitat destruction. Russian cargo airplanes, decommissioned elsewhere, haul out of unlicensed dirt strips in the jungle, connect up to black markets in Antwerp and Brussels, and across to subcontracted low-cost manufacturers in inland China (Redmond 2001). This is not a simple chain of cause and effect in the Baconian fashion. It is a Web: largely self-sustaining, multi-nodal, diverse, resilient and ever-changing. As such it cannot easily be reconciled with the linear modelling assumptions of ergonomics. Nevertheless, the effects are real and profound. Our thesis here is that ergonomics, as a scientific discipline, has at least theoretically to be concerned with and cognizant of such reticulations so that its own actions and effects can be assessed accordingly.

\section{Emergence, complexity and sustainability}

Therefore, we argue that it is ultimately self-defeating to seek to create sustainability in discrete areas of the world. Such a strategy is also insufficiently supported by an instrumental science or practice. Armstrong (2006) reminds us how in an early Platonic dialogue Socrates asked one of his companions what makes something beautiful. 'Gold', came back the reply. At that time, beautiful things were often made of gold. What excited Socrates was that this was fundamentally the wrong kind of answer. Some gold things are beautiful; some are not. Adding gold by itself will not transform the ugly into the beautiful. Sustainability is, with respect to Socrates' idea, rather like beauty: a hugely complex and emergent notion (Armstrong 2006). There is no simple formula by which we can reliably engineer new products that have such a property. This is, and always has been, the tension between engineering and emergence (Cilliers 2002). Engineering is about tooling around with parts, components, bits and pieces - and about the hope, or taken-for-granted assumption, that the quality of the constituted system will be subsumed in the quality of the constituent parts. Emergence means that the character of the system cannot be determined by an analytical or reductive specification of its components. What components (or constituent materials like gold) have, the system does not necessarily have, and vice versa. An instrumental stance towards sustainability, in other words, cannot just make it so. As Cilliers (2005, p. 258) put it:

The knowledge we have of complex systems is based on the models we make of these systems, but in order to function as models - and not merely as a repetition of the system - they have to reduce the complexity of the system. This means that some aspects of the system are always left out of consideration. The problem is confounded by the fact that that which is left out, interacts with the rest of the system in a non-linear way and we can therefore not predict what the effects of our reduction of the complexity will be, especially not as the system and its environment develops and transforms in time.

An emergent property is a characteristic of a complex open system, which cannot be deduced solely by examining the components of the system in isolation. Emergence is a result of a complex set of non-linear interactions between all the elements comprising the system. Again, this insight is in opposition to the reductive assumptions of conventional ergonomic theory. Paradoxically, some sustainable technologies maintain lifestyle status quo in the West and do not contribute to sustainability overall - because of emergent effects. Replacing lead with cassiterite in tin plating creates a more environmentally friendly product (also for disposal or recycling it at the end of its life), but demand for it has reverberated into fighting over deposits, with warlords and renegade Congolese forces battling for control in province of North Kivu. Such warfare has complex environmental and humanitarian repercussions similar to those in the tussle for coltan (Redmond 2001). Increasing ethanol content in fossil fuels reduces local or national carbon dioxide emissions, but has an inflationary effect on food prices and contributes to other 
environmental problems (Sauser 2007). The switch to low-energy light bulbs may help curb electricity demand (and in turn carbon dioxide emissions), but introduces more mercury into the environment at the end of the bulb's lifecycle (BBC 2008). Enticing consumers (e.g. with tax incentives) to install solar panels or purchase wind-generated energy makes local sense. But already questions swirl around the lasting wisdom of increasing Chinese manufacturing dominance in solar panels and wind turbines (GENI 2010). If we assess sustainable development along this avenue in Hendrick's terms, it may be good neither for a worldwide standard in ergonomics or health and safety, nor for the West's economics. Therefore, ergonomics may stand in the paradoxical position of achieving its goals in terms of design and efficiency, while simultaneously acting to reduce and eventually destroy the quality of human life.

\section{Complexity, ethics and sustainability}

Taken together, these concepts force ergonomic practitioners to address questions about the good society. How can ergonomic practice be reconciled with the poorly understood idea of sustainability, for example? How should it attempt to deal with the unintended consequences of actions taken in complex and emergent systems? These are, in themselves, huge and important questions and it is our intention here to open them up for debate within the intellectual community of ergonomic scholars. The ethical issues that these concepts raise, however, are quite clear. For example, the long forward shadow cast by the idea of sustainability raises numerous important ethical problems. The issue of intergenerational responsibility is a familiar one in social and political thought and has become central to those whose primary interest is with 'green' or ecological theory. What is our responsibility to future generations with regard to the environmental legacy that we bequeath them? In debates about sustainability, this ethical issue is perhaps the most important one facing us. Whereas we might well feel that we are responsible to those who come after us, we will never be held to account by them in any way that affects our own momentary quality of life. Most likely, we will not be there in that future, after all. This affords us endless room for procrastination and can make local sustainability initiatives look rather attractive for the time being. Even if the consequences do not lie in the future, the logic of the capitalist consumer market that has come to dominate global political economy still allows us to abdicate responsibility. That economy is partly built, after all, on an asocial and anti-consequentialist ethic. Anti-consequentialism here means that the economic and political configurations encourage us to believe that we do not have a responsibility for actions that are beyond our immediate vision or control (Devlin 1987). This might be due to either a lack of knowledge about the consequences of one's actions or simple indifference. It is a very powerful ideology that helps sustain many of the inequities of the current global political economy (Wilkin 2009). Thus, in the current global political economy, the responsibility of the consumer extends no further than paying for goods that are legally sold. For example, when we purchase a bar of chocolate there is approximately a $40 \%$ chance that the cocoa used to make it is the product of modern slave labour (Bales 2009). Do we have a particular moral responsibility here? Strictly speaking, in terms of the consumerism that dominates market societies, we do not (Sklair 1995). Our only moral responsibility is to pay the retailer and producer for the item. However, if the more complex Web of connections becomes visible to us, it might make a difference to our actions and the lives of those affected by them. It might lead us to challenge unjust social relations as was seen with the boycott of goods produced by companies who have used child labour. This problem is coupled with the fact that we live in market societies where the emphasis is on immediate and short-term returns. It means that, in practice, there are many ways and means by which we can (and are encouraged to) avoid this responsibility, not least by consumerism itself.

The key, of course, is that the complex and often distant relationships of Western consumerism become visible to us and that we come to recognise that our lives and actions or choices are integrated in deep and profound ways. Complexity and emergence connect here in ways which illuminate starkly the ethical dilemmas facing ergonomics. Some negative effects are visible close by and early on, which should help. Recall how George H.W. Bush announced at the 1992 Earth Summit in Rio de Janeiro that 'the American way of life is not negotiable'. But efforts to stretch that non-negotiable way of life by making it more sustainable could eventually be undermined by shifting global economic configurations. When the West uses its national tax revenues to help China supply its turbines and solar panels, for example, it adds to the evisceration of local manufacturing, technical expertise and export bases (GENI 2010). Local, componential sustainability can miss the interactions and reverberations and interconnections that proliferate from such commitments. These complexities, stirred into existence by local Western sustainability pledges, need to be considered by ergonomics, but it can do that only if it counts its responsibilities in terms that are wider than those of a closed system of study whose individual parts can be separated, measured, controlled and safely bounded (Wilkin 2009). The problem of sustainability is a global one and therefore requires ideas which move 
from the local to the global. These will need to encourage us to move beyond the conventional view of societies and their problems as being bounded within nation-states (a form of closed social system) to one which embraces the global nature of our practices, relations and increasingly our institutions.

What is required for sustainability is not the limited evolution of parochial adjustments but rather a genuine global advocacy for complex system assessment. In practice, this means that the process of design must be held to its consequences - at least those that are reasonably foreseeable at this time. The process of manufacturing and the cost of goods and services must include lifecycle considerations, and possibly include costs for repair of previous collateral damage. Such strategies can only be achieved if many applicable sciences embrace the need to incorporate the ramifications of complexity. Surely ergonomics needs to be one of these. There is a further reason for that. Focusing on local sustainability may do little to critically evaluate, let alone influence, the activity overall. Take, for instance, conversion of automobile commuting to electrical power. This makes sense if sustainability gets measured in the reduction of environmentally harmful exhaust gasses. However, converting the same activity to more of the same (if by slightly different means) does not necessarily emancipate much. Such commuting, independent of its fuel source, frequently links to unsustainable ills such as socio-economic segregation, community erosion and green-site land depletion (Byrne 1998). While perpetuation of such activities may benefit existing economic configurations dominated by large institutions (e.g. electricity generation and distribution), the aggregate action can be hegemonic and detrimental to quality of life (McLean and Elkind 2004, Wilkin 2009). Sustainability (both locally and globally) is going to be helped if such social and ecological complexities are taken into account. This, in turn, can be done only when ergonomics recognises its own role in sustaining a global political economy that perpetuates a lack of global sustainability.

\section{Conclusion}

One way to help realise ergonomics of sustainability is to define it not as something reductive (thereby adding one more variable to a closed system of study) but as something in which we must actively embrace complexity and emergence and all of its daunting challenges. This will involve a careful examination of the curricula of ergonomics education as well as their foundational epistemologies and common practices. Degree programmes in ergonomics have often taken the instrumental as coincident with both the scientific and pragmatic: two enduring aspirations of the discipline (Parasuraman et al. 2008, Dekker et al. 2010, Lützhoft et al. 2010). This arrangement assures a supply of ergonomists whose interests are easily intertwined with the pursuits of dominant institutions and industries which create the problems that ergonomics needs to take care of (Wilkin 2009). Continuing such a philosophy will make it almost impossible for ergonomics to take sustainability seriously. Commerce and sustainability will keep competing; ergonomics and economics will side with one another - if for no other reason than its paradigm, this consensus around a set of institutional procedures and practices and expectations that ergonomics has become configured in. Consensus, however, is never a compelling argument in itself. Indeed, in democracy and science, consensus can equate to conformity and the abnegation of critical thought.

If ergonomists are to meaningfully, freely, imaginatively engage with complexity, with relationships and their emergent properties, then enriching the amount and depth of historical and critical scholarship in the discipline is a crucial point of departure. Understanding emergence has not been easy for ergonomics given its particular epistemological foundations. This should not come as a surprise if Kuhn's idea of a paradigm is correct. Emergence falls outside the parameters of what passes for normal science in ergonomics and to embrace it requires a radical rethinking of what ergonomics might achieve. There is an intrinsic value in enhancing ergonomics education and practice by engaging with ideas from the humanities and the social sciences. The latter are far more involved with debates about the relationship among complexity, emergence, sustainability and ethics.

There is also an instrumental value in teaching and integrating more humanities and social science in ergonomics work. In addition to helping us to ask critically what sustainability is, or what a fair distribution of resources is, it can turn us to core, pragmatic questions such as how sustainability or fair distribution can be achieved. Thus, in order to understand processes designed to move us towards sustainability, we must be prepared within our science to think outside its current paradigm. We must not be afraid of nor shy away from a robust discussion on values, nor from making value statements. This is what helps lead to a purposeful engagement with the wider world (Armstrong 2011). Interestingly, ergonomics has always had links with conceptions of a good society through its relationship to trade unions who acted as early champions of ergonomics. So what we are proposing is not alien to the discipline but instead is asking it to engage with something that has had marginal impact in the discipline. 
Thus, we conclude by making three substantive points about the relationship between ergonomics and sustainability. Firstly, sustainability is a concept that creates problems whose solutions currently fall outside the parameters of normal science in ergonomics. Secondly, complexity and emergence represent two concepts that cannot be reconciled with the positivist philosophy underpinning ergonomics. We have shown with examples the ways in which these problems cannot be mapped onto the linear scientific notions at the heart of ergonomic theory and practices. Thirdly, engaging with ethical questions is unavoidable in any discipline dealing with human subjects, and ergonomics has a meaningful part to play in debates about the good society and how we should live.

\section{References}

Antonsen, S., 2009. Safety culture and the issue of power. Safety Science, 47 (2), 183-191.

Armstrong, J., 2006. The secret power of beauty: why happiness is in the eye of the beholder. New York, NY: Penguin Global. Armstrong, J., 2011. In search of civilization: remaking a tarnished idea. Minneapolis, MN: Graywolf Press.

Bales, K., 2009. Modern slavery: the secret world of 27 million people. London: One World Publications.

BBC, 5 Jan 2008. Low-energy bulb disposal warning. Available from: http://news.bbc.co.uk/2/hi/uk_news/7172662.stm [Accessed 20 Jun 2011].

Byrne, D.S., 1998. Complexity theory and the social sciences: an introduction. London: Routledge.

Capra, F., 1996. The web of life: a new scientific understanding of living systems. 1st Anchor Books ed. New York, NY: Anchor Books.

Carayon, P., 2010. Human factors in patient safety as an innovation. Applied Ergonomics, 41 (5), 657-665.

Cilliers, P., 1998. Complexity and postmodernism: understanding complex systems. London: Routledge.

Cilliers, P., 2002. Why we cannot know complex things completely. Emergence, 4 (1/2), 77-84.

Cilliers, P., 2005. Complexity, deconstruction and relativism. Theory, Culture \& Society, 22 (5), 255-267.

Dekker, S.W.A., 2005. Ten questions about human error: a new view of human factors and system safety. Mahwah, NJ: Lawrence Erlbaum.

Dekker, S.W.A., 2011a. Drift into failure: from hunting broken components to understanding complex systems. Farnham, UK: Ashgate.

Dekker, S.W.A., 2011b. What is rational about killing a patient with an overdose? Enlightenment, continental philosophy and the role of the human subject in system failure. Ergonomics, 54 (8), 679-683.

Dekker, S.W.A., Nyce, J.M., van Winsen, R., and Henriqson, E., 2010. Epistemological self-confidence in human factors research. Journal of Cognitive Engineering and Decision Making, 4 (1), 27-38.

Dekker, S.W.A., Cilliers, P., and Hofmeyr, J., 2011. The complexity of failure: implications of complexity theory for safety investigations. Safety Science, 49 (6), 939-945.

Devlin, P., 1987. The enforcement of morals. Oxford: Oxford University Press.

Endsley, M.R., 1995. Measurement of situation awareness in dynamic systems. Human Factors, 37 (1), 65-84.

Feyerabend, P., 1993. Against method. 3rd ed. London: Verso.

Flach, J.M., 1995. Situation awareness: proceed with caution. Human Factors, 37 (1), 149-157.

Flach, J.M., Dekker, S.W.A., and Stappers, P.J., 2008. Playing twenty questions with nature: reflections on the dynamics of experience. Theoretical Issues in Ergonomics Science, 9 (2), 125-155.

Foucault, M., 1970. The order of things: an archaeology of the human sciences. London: Tavistock.

GENI, 2010. Chinese dominance in clean energy equipment will have worrying effect on energy politics. Available from http:// www.geni.org/globalenergy/library [Accessed 20 August 2012].

Goh, Y.M., Brown, H., and Spickett, J., 2010. Applying systems thinking concepts in the analysis of major incidents and safety culture. Safety Science, 48 (3), 302-309.

Hancock, P.A., 2009. Mind, machine and morality: toward a philosophy of human-technology symbiosis. Aldershot, UK: Ashgate.

Hancock, P.A. and Drury, C.G., 2011. Does human factors/ergonomics contribute to the quality of life? Theoretical Issues in Ergonomics Science, 12 (3), 1-11.

Hancock, P.A., Weaver, J.L., and Parasuraman, R., 2002. Sans subjectivity: ergonomics is engineering. Theoretical Issues in Ergonomics Science, 45, 991-994.

Heylighen, F., Cilliers, P., and Gershenson, C., 2006. Complexity and philosophy. Brussel, BE: Vrije Universiteit Brussel and Evolution, Complexity and Cognition.

Hutchins, E.L., 1995. How a cockpit remembers its speeds. Cognitive Science, 19 (3), 265-288.

Kuorinka, I., 1990. Ergonomics in the future: the next leg. Ergonomics, 33 (3), $283-285$.

Lützhoft, M.H., Nyce, J.M., and Petersen, E.S., 2010. Epistemology in ethnography: assessing the quality of knowledge in human factors research. Theoretical Issues in Ergonomics Science, 11 (6), 532-545.

McLean, B. and Elkind, P., 2004. The smartest guys in the room: the amazing rise and scandalous fall of Enron. New York, NY: Portfolio.

Meister, D., 1999. The history of human factors and ergonomics. Mahwah, NJ: Lawrence Erlbaum.

Page, S.E., 2008. Uncertainty, difficulty and complexity. Journal of Theoretical Politics, 20 (2), 115-149.

Parasuraman, R., Sheridan, T.B., and Wickens, C.D., 2008. Situation awareness, mental workload and trust in automation: viable, empirically supported cognitive engineering constructs. Journal of Cognitive Engineering and Decision Making, 2 (2), $140-160$.

Redmond, I., 2001. Coltan Boom, Gorilla Bust: the impact of coltan mining on gorillas and other wildlife in eastern DR Congo. London: The Dian Fossey Gorilla Fund Europe and the Born Free Foundation. 